\title{
A Study on Risk Management in Evaluation of Enterprise Business
}

\author{
Yuko Iwasaki a,", Kenji Watanabe ${ }^{\text {, }}$ \\ ${ }^{a}$ Yokkaichi University, Yokkaichi, Mie, 512-8512 Japan \\ ${ }^{\mathrm{b}}$ Nagoya Institute of Technology, Nagoya, Aichi, 466-8555 Japan
}

\begin{abstract}
As for the risk management of the financial institution, a change is demanded to risk permission based on risk appetite from the risk aversion corresponding to the bad-loan problem. The financial institutions which performed risk management based on VaR (value at risk) fell into a situation of the management aggravation by the outbreak of the global financial crisis. They used an index to measure based on a past price change statistically.

Many local financial institutions work on "business evaluation" included there since 2014. In 2016 Financial Services Agency demand "an evaluation (= business evaluation) depending on growth possibility of the business of the client appropriately without depending on a security, a guarantee excessively for a financial institution". In this way, policy demands switching the financing posture that came to the local financial institution depending on a security, a guarantee to the financing based on the business evaluation"

Authors suggest a scheme to evaluate business value and risk and connect with the financing for the new risk that is hard to become an insufficient measurement with the conventional risk management model.

In this study, authors analyzed the structure of the risk management when financial institution financed by business evaluation and decided the evaluation of the risk from the influence of the factor of the individual risk, and showed decision-making model,
\end{abstract}

Keywords: Risk management, Business Evaluation Regional Financial Institution, AHP (Analytic Hierarchy Process)

\section{Introduction}

At the world financial crisis after the Lehman shock of 2008 , it has it pointed out that the risk management that a financial institution performed as one factor that a crisis extended conventionally was not able to cope with new financial products and finance innovation such as the securitized paper enough. By the conventional risk management, it remained in correspondence to unify these mainly on the quantification of a market risk and the credit risk in total.

The financial institutions which performed risk management based on $\mathrm{VaR}$ (value at risk) fell into a situation of the management aggravation by the outbreak of the global financial crisis. They used an index to measure based on a past price change statistically it is the amount of expectation's greatest loss evaluated within the specific probability, and how assets holding now may lose it for an absolute amount of money within a specific tenure when financial assets for a certain period with VaR.

The loans to the company do not increase, and there is the lending-to-deposit rate of the bank in a tendency to drop while a risk diversifies and becomes complicated. The local financial institution has an important management problem while population decreases in many areas of the local area in Japan, and the economic activities are sluggish.

Many local financial institutions work on "business evaluation" included there since Financial Services Agency announces, "a finance monitoring basic policy" under such situation in September 2014. Furthermore, in " 2016 finance administration policy that Financial Services Agency announced in October, 2016," policy demand, "an evaluation (= business evaluation) does contents or growth possibility of the business of the client appropriately without depending on a security, a guarantee excessively for a financial institution" for "security of enough display of the finance interagency and healthy financial system". In this way, policy demands switching the financing posture that came to the local financial institution depending on a security, a guarantee to "the financing based on the business evaluation"

Authors suggest a scheme that an area financial institution evaluate business value and risk, and connect 
with the financing for the new risk that is hard to become an insufficient measurement with the conventional risk management model.

\section{Methodology}

\subsection{Phase of Business}

At first, authors classified "the business" that a financial institution evaluated for 3 phases of the "conception" "realization" and "utilization".

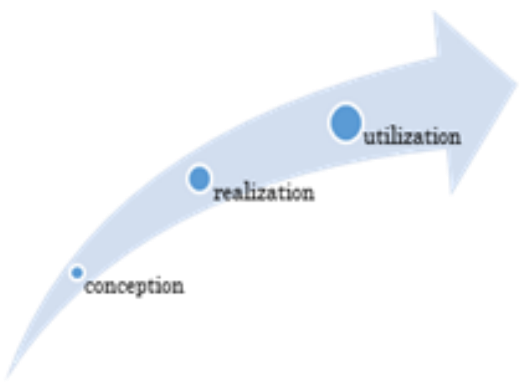

Figure1 Phase of business

The conception is a design plan, and the realization contains a detailed design of the embodiment of the business, construction, the proof of the system. Furthermore, the utilization is a form to provide a product, service with a system.

\subsection{Structure of Business}

The structure of the business at each phase consists of profitability, cost, and risk. Furthermore, risk has two categories, internal risk (risk(i), Fig2) and external risk (risk(e)). The internal risk is the risk of the category hat the business main constituent controls it and can have an influence on, and the external risk is the risk of the category that it is driven by business and controls it and cannot have an influence on (market trend, risk of the policy change of the government). To make decision-making model authors use AHP (Analytic Hierarchy Process) and decomposed into a hierarchical structure.

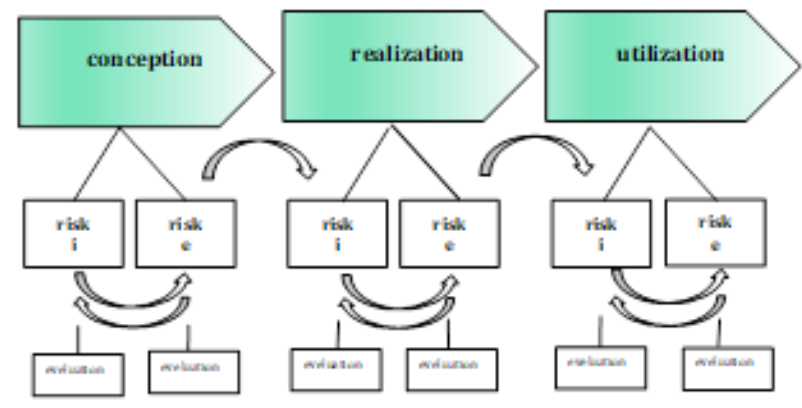

Figure2 AHP (Analytic Hierarchy Process)

-Influence of the risk

The financial institution evaluates profitability, cost, and risks in each phase. In "conception" phase, the profit does not appear and it does not cost. In "realization" phase, the profit does not appear and the cost is comparatively low. In both phases, it is important for financial institutions to evaluate risk. In "utilization" phase, financial institutions evaluate profit/cost and risk for financing.

Furthermore, the individual risk affects other risks. For example, the external risk of the conception phase affects the internal risk of the same phase.

The risk may have an influence on next phase. The external risk of the conception phase may have an influence on the internal risk of the realization phase.

\subsection{Business Evaluation Framework}

Along structure of the business showed above, authors show a framework for business evaluation and set an evaluation point.

As mentioned, evaluation point 1 means that there are few problems in profitability/cost/risk. 3 means standard level and 5 means there are difficult problems not easily resolved in profitability/cost/risk. Next table is the sample. In "conception" phase, the profit does not appear and it does not cost. In "realization" phase, the profit does not appear and the cost is comparatively low.

Table.1 Business Evaluation Framework

\begin{tabular}{|l|l|l|l|}
\hline Points/Phase & conception & realization & utilization \\
\hline profitability & & & \\
\hline cost & & & \\
\hline risk(i) & & & \\
\hline risk(e) & & & \\
\hline
\end{tabular}

Evaluation point:

1 few problems $\quad 2$ a few problems 
3 standard level 4 difficult problems

5 difficult problems not easily resolved

Next table is the sample. In "conception" phase, the profit does not appear and it does not cost. In "realization" phase, the profit does not appear and the cost is comparatively low.

Table.2 Business Evaluation Framework (Sample)

\begin{tabular}{|l|c|c|l|}
\hline Points/Phase & conception & realization & utilization \\
\hline profitability & 1 & 1 & \\
\hline cost & 1 & 3 & \\
\hline $\operatorname{risk}(\mathrm{i})$ & & & \\
\hline $\operatorname{risk}(\mathrm{e})$ & & & \\
\hline
\end{tabular}

Evaluation point:

1 few problems

2 a few problems

3 standard level

4 difficult problems

5 difficult problems not easily resolved

\section{Model of decision making}

Next table 3 express the structure of decision-making model for financial institutions. Several factors affected on other factors of same phase or next phase. For example, the external risk factor of the conception phase affected factor of the internal risk of the same phase. And risk factors of the conception phase affected risk factors of the realization phase.

Table. 3 Model of decision making (1)

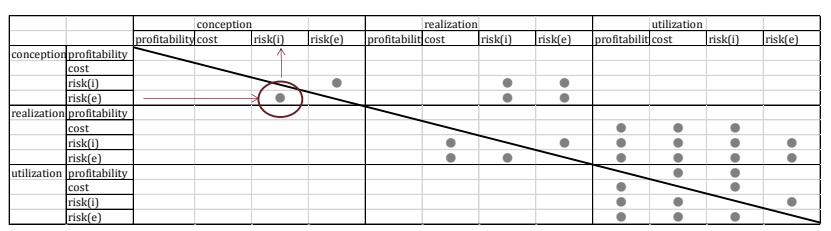

Table.4 Model of decision making (2)

\begin{tabular}{|l|l|l|l|l|l|l|}
\hline & \multicolumn{2}{|c|}{ conception } & \multicolumn{3}{c|}{ realization } \\
\cline { 2 - 7 } & profitability cost & risk(i) & risk(e) & profitabilit)cost & risk(i) & risk(e) \\
\hline conception profitability & & & & & & \\
\hline & & & & & & \\
\hline & & & & & & \\
\hline
\end{tabular}

Factors of the realization phase affected each factor of the utilization phase. This matrix suggested analysis of risks of realization is the main theme for business evaluation.

In the utilization phase factors affected each other.

Table.5 Model of decision making (3)

\begin{tabular}{|c|c|c|c|c|c|c|c|c|}
\hline & & \multicolumn{3}{|c|}{ realization } & \multicolumn{4}{|c|}{ utilization } \\
\hline \multirow{2}{*}{ realization } & \multirow[b]{2}{*}{ profitability } & profitability cost & \multirow[t]{2}{*}{$\operatorname{risk}(i)$} & \multirow[t]{2}{*}{ risk(e) } & \multicolumn{2}{|c|}{ profitabilit) } & \multirow[t]{2}{*}{ risk(i) } & \multirow[t]{2}{*}{ risk(e) } \\
\hline & & & & & & & & \\
\hline & cost & & & & - & - & - & \\
\hline & risk(i) & & & - & - & 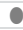 & c & - \\
\hline & risk(e) & & 0 & & e & 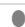 & c & - \\
\hline
\end{tabular}

Table.6 Model of decision making (4)

\begin{tabular}{|c|c|c|c|c|c|}
\hline & & & utilization & & \\
\hline & & profitability & cost & risk(i) & risk(e) \\
\hline \multirow[t]{4}{*}{ utilization } & profitability & 3 & 0 & 0 & \\
\hline & cost & O & & 0 & \\
\hline & risk(i) & 0 & 0 & & 0 \\
\hline & risk(e) & 0 & 0 & O & \\
\hline
\end{tabular}

publication. Once an eligible paper is accepted, it will be published under a Creative Commons Attribution 3.0

(CC BY 3.0) License.

\section{Function of crowdfunding}

In recent years, many venture companies that provide innovative financial services using technology, which is a field known as "FinTech", have appeared and companies other than traditional financial institutions such as retailers, are seen providing new financial services.

This is since technological innovation including IoT technology, big data and artificial intelligence have significantly changed the relationship between finance and industry, and the need for new, previously unheard-of financial services have been emerging.

For example, a new mechanism for procuring capital through the Internet has been attracting interest. As it involves obtaining the funding from large numbers of the investors, it is called crowdfunding.

Crowdfunding has several types, such as equity based crowdfunding, donation based, lending based and reward based. From the viewpoint of business-related evaluation of the financial institution, authors focus on lending based and 
reward based crowdfunding.

In lending based and reward based crowdfunding, platform are interests in profitability of project and raise funds for the project, This funding is similar to business-related evaluation of the financial institution.

In indirect financial sieves, financial institution are ordinary interested in financial information and data of enterprise, as mentioned above regional financial institutions are required to exercise their financial intermediary function in their regions by further promoting "relationship banking," in particular.

To add crowdfunding function as the new business model for financial institution, several reformations is necessary.

1 , find new seeds of business and evaluate

2. raise funds for the business/project

3.develop the method of return, and others.

Figurr3 financial services of regional financial institute

\section{Conclusions}

As for the risk management of the financial institution, a change is demanded to risk permission based on risk appetite from the risk aversion corresponding to the bad-loan problem, and to the qualitative analysis that the business-related evaluation adopted from quantitative analysis mainly on conventional $\mathrm{VaR}$ and the financing information. Financial Services Agency of Japan demands the financing posture that came to the local financial institution depending on a security, a guarantee to "the financing based on the business evaluation".

In this study, authors analyzed the structure of the risk management when a local financial institution financed it by a business evaluation and decided the evaluation of the risk from the influence of the factor of the individual treatment risk, and accommodations showed decided structure.

indirect financial services

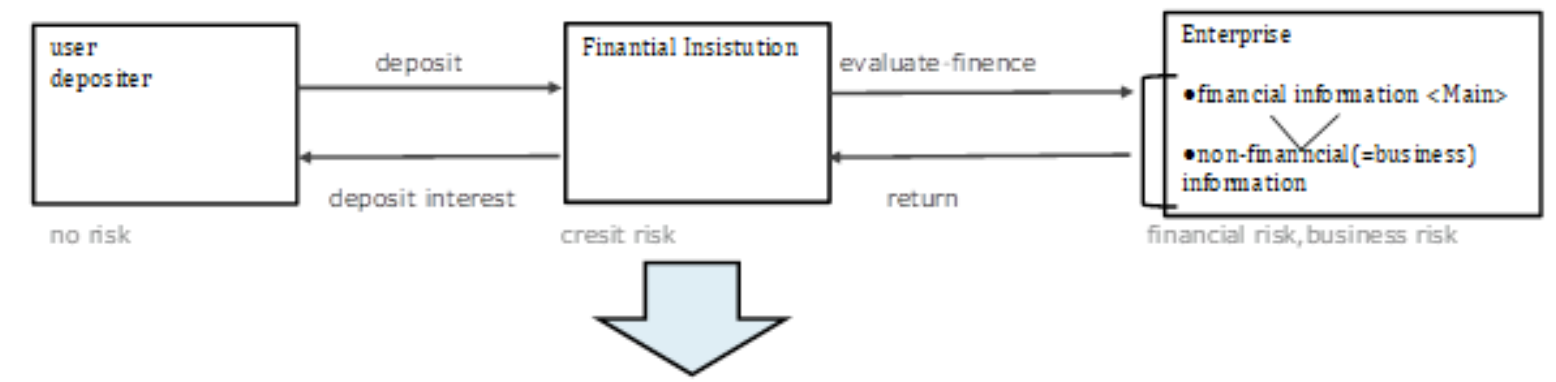

financial services of regional financial institution
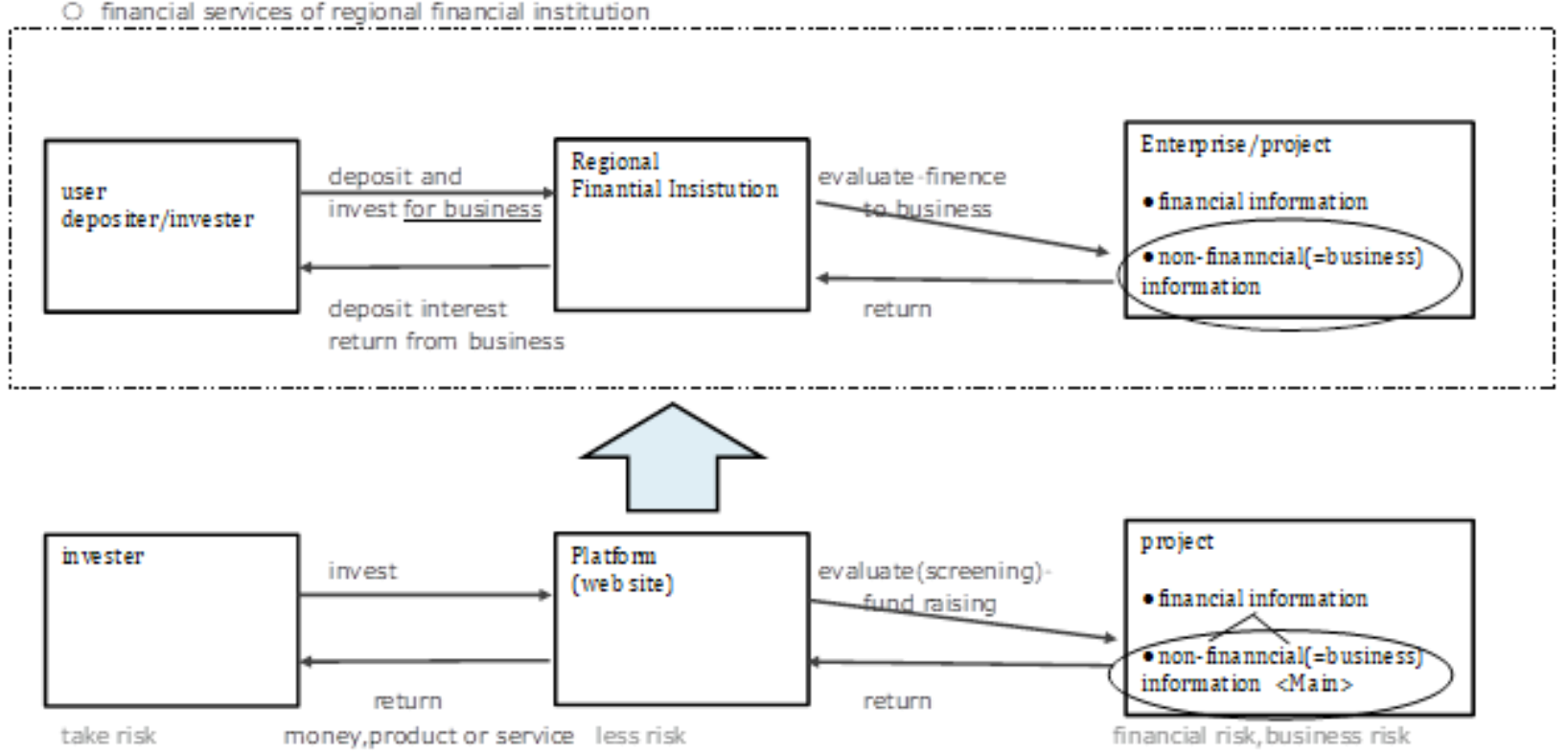

Crowd funding system 


\section{References}

(1) Financial Services Agency ( 2014 ) " Business Evaluation by Regional Financial Institution” (in Japanese)

(2) Financial Stability Board 2013a "Thematic Review on Risk Governance" http://www.financialstabilityboard.org/.

(3) Financial Stability Board 2013b, "Principals for An Effective Risk Appetite Framework," http://www.financialstabilityboard.org/.

(4) Mizuho Financial Group website (in Japanese) http://www.mizuho-fg.co.jp/index.html

(5) Mizuho Research Institute (2014)" Bank Management after financial crises" (in Japanese)

(6) PwC 2015 "Risk governance, risk appetite framework, risk culture" (in Japanese) http://www.pwc.com/jp/ja/japanknowledge/archive/risk -governanceappetite-framework1502.jhtml.

(7) Shigenobu OHARA (2017) "The Exploration of Value Design Review and Integration Skill-Quantified Visibility Tools for Architect Jump Methodology"Journal of International Association of P2M Vol.11 No.2, pp.1-18, 2017 (in Japanese)

(8) Small and Medium Enterprise Agency,"2016 White Paper on Small and Medium Enterprises in Japan"((in Japanese)

(9) Yuko IWASAKI "Possibility of Crowdfunding about Regional Finance" The Journal of Yokkaichi University, 28(1), 93-106, 2015 (In Japanese)

(10) Yuko KAWAMOTO 2015, "Management for Financial Institutions" Toyo Keizai, Inc. (in Japanese) 